\section{Genetic mechanism and tectonic significance of postglacial conglomerate accumulation at Diexi in the eastern Tibet}

\author{
SIQI ZHANG ${ }^{1,2}$, HANCHAO JIANG ${ }^{1}$, JIAWEI FAN ${ }^{1}$, \\ HONGYAN XU ${ }^{1}$, WEI SHI ${ }^{1}$, QIAOQIAO GUO ${ }^{1,2}$ AND \\ XIAOTONG WEI ${ }^{1,2}$
}

${ }^{1}$ State Key Laboratory of Earthquake Dynamics, Institute of Geology, China Earthquake Administration

${ }^{2}$ College of Earth and Planetary Sciences, University of Chinese Academy of Sciences

Presenting Author: 604100698@qq.com

Tectonic or climatic significance of conglomerate accumulation in the tectonically active regions has raised a hornets' nest of controversy. This paper discusses the formation mechanism and geological significance of conglomerates in Diexi, eastern TP. This gravel layer is retained in the Diexi lacustrine section. By studying the chronology of the entire section, the gravel layer in the Diexi lacustrine section in the eastern Tibetan Plateau is dated to $16.79 \mathrm{ka} \mathrm{BP}$. The bending of lacustrine layer caused by gravity collapse of massive rocks is clearly observed in the Diexi section. The lacustrine layer under the gravel layer was severely disturbed with a V-shape bending scale from $2 \mathrm{~m}$ to $3 \mathrm{~m}$. From the north to the south of the section, the lacustrine layer kept continuous and showed no sign of erosion by the collapse debris. Under the severe effect of gravity, rocks fell or slid along a steep hillside and impacted the dammed lake floor in free fall and ploughed into the lacustrine beds. Consequently, the unconsolidated sediments were liquefied and fluidized and generated large-scale folds that may be accompanied by small interlayer glide structures. Furthermore, the gravel layer is covered directly by a lacustrine layer without up-fining gradation of particles or sedimentation bedding between lacustrine and gravel layers. These evidences suggest that the rock mass may collapse under a strong force and fall rapidly into the lake. Considering the frequency of earthquakes in this area, it is more likely that these gravel deposits were caused by an earthquake instead of a debris flow caused by torrential rain. Detailed analysis of satellite images and the sedimentary characteristics of gravel layer identified an ancient landslide at the west bank of Minjiang River near the Muer village, lying closely north of the Diexi section. Analysis of the intensity attenuation model in Southwest China implies that the lower limit of the minimum earthquake magnitude to trigger the landslide is $M_{S}>5.7$. This study is of great significance for our understanding of the genesis of gravel accumulation in areas with complex climatic and tectonic conditions.

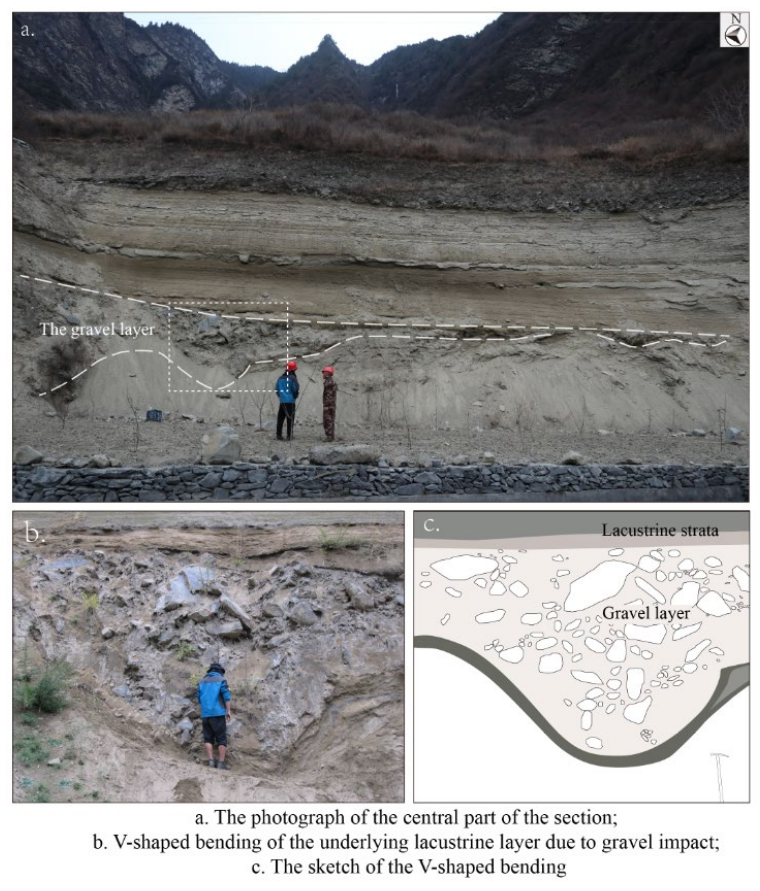

Lei et al., 2007

The fitting formula of the elliptic model used is:

Long axis: $I_{a}=d_{a 1}+d_{a 2} M+d_{a 3} \lg \left(R_{a}+R_{a 0}\right)+\varepsilon_{a}$

Minor axis: $I_{b}=d_{b 1}+d_{b 2} M+d_{b 3} \lg \left(R_{b}+R_{b 0}\right)+\varepsilon_{b}$

\begin{tabular}{ccccccc}
\hline Area & Axial direction & $\mathrm{d}_{1}$ & $\mathrm{~d}_{2}$ & $\mathrm{~d}_{3}$ & $\mathrm{R}_{0}$ & $\sigma$ \\
\hline Southwest & long axis & 7.3568 & 1.2780 & -5.0655 & 24 & 0.70 \\
of & short axis & 3.9502 & 1.2780 & -3.7567 & 9 & 0.70 \\
Sichuan & mean axis & 5.3603 & 1.2963 & -4.3666 & 15 & 0.51 \\
\hline Sichuan & long axis & 4.0293 & 1.3003 & -3.6404 & 10 & 0.45 \\
basin & short axis & 2.3816 & 1.3003 & -2.8573 & 5 & 0.45 \\
& mean axis & 3.3727 & 1.2755 & -3.2858 & 7 & 0.42 \\
\hline
\end{tabular}

